\title{
Produção de biomassa e do rendimento do óleo essencial de melissa em cultivo solteiro e consorciado com mil-folhas e alface
}

\author{
Biomass production and essential melissa oil output evaluation in a single and linked crop \\ cultivation to both yarrow and lettuce
}

\author{
Débora Soares Brandão $^{I^{*}}$ Pedro Henrique Lopes Silva ${ }^{\mathrm{I}}$ Yuri de Gennaro Jaruche ${ }^{\mathrm{I}}$ \\ Rizia Rodrigues Santos ${ }^{I}$ Ernane Ronie Martins ${ }^{I}$
}

\section{RESUMO}

\begin{abstract}
O trabalho teve como objetivo avaliar a produção da biomassa e o rendimento de óleo essencial da melissa, quando em cultivo solteiro e consorciada com mil-folhas e alface. Os tratamentos consistiram em melissa em cultivo solteiro, melissa em consórcio com mil-folhas, melissa consorciada com alface, milfolhas e alface em cultivo solteiro. $O$ delineamento experimental utilizado foi o inteiramente casualizado com cinco tratamentos $e$ seis repetições. Foram avaliados o teor e o rendimento do óleo essencial da melissa e a matéria fresca e a matéria seca da parte aérea de todas as espécies. Notou-se, a partir dos valores das médias, que o cultivo consorciado de melissa com alface proporcionou maior rendimento de óleo essencial, matéria fresca e matéria seca. Os menores valores de todas as variáveis foram observados no cultivo solteiro da melissa. Considerando o Uso Eficiente da Terra (UET), o cultivo consorciado da mil-folhas e da alface com a melissa gerou bons rendimentos de biomassa das plantas, pois os valores calculados para as espécies foram superiores a 1,0. O cultivo consorciado das espécies não interferiu significativamente no teor do óleo essencial da melissa.
\end{abstract}

Palavras-chave: Achillea millefolium L., Lactuca sativa L., Melissa officinalis L., plantas medicinais.

\section{ABSTRACT}

The research aimed to evaluate melissa's biomass production and its essential oil output, both single cultivation and linked cultivation to yarrow and lettuce. The treatments were consisted in single cultivantion melissa, melissa linked to yarrow, melissa linked to lettuce, yarrow and lettuce in single cultivation. The experimental design used was a totally randomized design with five treatment and six repetitions. Was evaluated the content and the yield of essential oil of melissa, the fresh matter and the dry matter of the aerial part of all species. It was seen from the average valuations that the melissa linked cultivation to the lettuce obtained the greatest output, fresh matter and dry matter. The smaller values of all variables was observed in melissa in single cultivation. To the the Effective Land Use (ELU), the yarrow and lettuce linking cultivated to the melissa generated good species biomass output, because the calculated results to the plants were higher than 1,0. The species linking cultivation did not interfere significantly in melissa's essential oil content.

Key words: Achillea millefolium L., Lactuca sativa L., medicinal plants, Melissa officinalis $L$.

\section{INTRODUÇÃO}

A espécie Melissa officinallis L. (Lamiaceae) é originária de Portugal e Ilha da Madeira, sendo cultivada também no Brasil (MARTINS \& PASTORI, 2004; LORENZI \& MATOS, 2008). Trata-se de uma planta herbácea, perene, aromática e com folhas membranosas (MARTINS \& PASTORI, 2004; LORENZI \& MATOS, 2008; RIBEIRO \& DINIZ, 2008). Apresenta utilização medicinal como antiespasmódico e calmante (CERNY \& SCHIMID, 1999; ROVERATTI, 1999; MARTINS et al., 2000). O óleo essencial da espécie possui atividades antioxidativa, antibiótica, antifúngica e antibacteriana com larga aplicação na indústria farmacêutica, cosmética e alimentícia (TEKEL et al., 1997; CERNY \& SCHIMID, 1999). A planta fresca possui cerca de 0,02 a $0,2 \%$ de óleos essenciais e sua composição assemelha-se a um dos quimiotipos de Lippia alba (Mill) N. E. Brown, sendo o citral, responsável pela ação relaxante da planta, e os monoterpenos, responsáveis pelo odor característico do óleo, considerados os constituintes majoritários

IInstituto de Ciências Agrárias (ICA), Universidade Federal de Minas Gerais (UFMG), 39404-547, Montes Claros, MG, Brasil. E-mail: deboranpr@hotmail.com.*Autor para correspondência. 
(MARTINS et al., 2000; SADRAEI et al., 2003; MARTINS \& PASTORI, 2004).

A Achillea millefolium L. (Asteraceae) é uma planta originária da Europa e Ásia (MARTINS et al., 2000; LORENZI \& MATOS 2008). Apresenta uso medicinal como antiespasmódica e cicatrizante, além de ser utilizada como ornamental e na preparação de compostos na agricultura biodinâmica (ROVERATTI, 1999; MARTINS et al., 2000; SARTÓRIO, 2000; LORENZI \& MATOS, 2008). É indicada para plantios em bordadura próximos a ervas aromáticas, uma vez que aumenta a produção de óleos essenciais das demais espécies (CORRÊA JÚNIOR et al., 2006).

Originária do sul da Europa e da Ásia Ocidental, a alface é pertencente à família Asteraceae (FILGUEIRA, 2007). É a hortaliça folhosa mais importante economicamente para o Brasil e com forte amplitude comercial, sendo cultivada em praticamente todas as regiões do país (VIDIGAL et al., 1995; CARVALHO FILHO et al., 2009).

As três espécies possuem um grande número de utilizações e são consideradas com potencial de mercado, tornando-se necessários estudos sobre os seus cultivos, avaliando os aspectos da produção que possam melhorar sua qualidade. $\mathrm{O}$ cultivo consorciado de duas ou mais espécies pode reduzir o risco do surgimento de pragas e doenças e aumentar a produção para espécies compatíveis. É necessário, entretanto, fazer um planejamento dessa consorciação, devido aos efeitos alelopáticos (CORRÊA JÚNIOR et al., 2006). Com essa forma de cultivo associado de plantas, as espécies companheiras podem estimular o crescimento e a produção de óleos essenciais em plantas medicinais (SILVA et al., 1999). Segundo MOTA et al. (2011), existe uma lacuna no estudo da utilização de consórcios, pela carência de dados relacionados a este sistema realizado entre diferentes tipos de plantas medicinais ou destas com hortaliças. De acordo com estes mesmos autores, levando-se em consideração a valorização do uso de plantas para fins medicinais e o aumento da procura por essa matéria-prima, tornam-se indispensáveis estudos que propiciem informações que permitam melhorar os processos de produção da biomassa vegetal, visando a incrementar ou mesmo manter os teores das substâncias de interesse.

Diante disso, o presente trabalho teve como objetivo avaliar a produção de biomassa e o rendimento do óleo essencial de melissa em cultivo solteiro e consorciado com mil-folhas e alface.

\section{MATERIAL E MÉTODOS}

O experimento foi realizado em casa de vegetação, nos meses de setembro de 2010 a janeiro de 2011, no Instituto de Ciências Agrárias da Universidade Federal de Minas Gerais - ICA/UFMG. Pela classificação Köppen, o clima predominante na região é o Aw - tropical de savana, com inverno seco e verão chuvoso.

O delineamento estatístico utilizado foi o inteiramente casualizado com cinco tratamentos e seis repetições. Os tratamentos consistiram em: T1melissa em cultivo solteiro (testemunha); T2: melissa em cultivo consorciado com mil-folhas; T3: melissa em cultivo consorciado com alface; T4: mil-folhas em cultivo solteiro; e T5: alface em cultivo solteiro. O experimento foi montado em vasos de 14 litros, sendo que cada vaso continha duas mudas da mesma espécie para os tratamentos com cultivo solteiro e uma muda de cada espécie nos tratamentos com cultivo consorciado, perfazendo, assim, sempre duas mudas por vaso.

A irrigação foi realizada manual e diariamente, assim como, também, o controle das plantas invasoras.

Os vasos foram preenchidos com substrato composto de solo, areia e esterco bovino curtido, na proporção de 3:2:1, cuja análise de fertilidade apresentou os seguintes atributos: $\mathrm{pH}\left(\mathrm{H}_{2} \mathrm{O}\right)=8,0$; $\mathrm{P}=480 \mathrm{mg} \mathrm{kg}^{-1} ; \mathrm{K}=920 \mathrm{mg} \mathrm{kg}^{-1} ; \mathrm{Ca}=4,50 \mathrm{cmol}_{c}$ $\mathrm{dm}^{-3} ; \quad \mathrm{Mg}=1,80 \mathrm{cmol}_{c} \quad \mathrm{dm}^{-3} ; \quad \mathrm{Al}=0 \mathrm{cmol}_{c} \quad \mathrm{dm}^{-3} ;$ $\mathrm{H}+\mathrm{Al}=0,76 \mathrm{cmol}_{\mathrm{c}} \mathrm{dm}^{-3} ; \mathrm{SB}=8,66 \mathrm{cmol}_{\mathrm{c}} \mathrm{dm}^{-3} ; \mathrm{V}=92 \%$ e Matéria Orgânica=4,23dag kg-1 .

As sementes de melissa e de alface adquiridas no comércio foram semeadas em bandejas de isopor de 128 células contendo substrato comercial Plantmax $^{\circledR}$. Utilizou-se a alface lisa 'Aurélia'. O transplantio ocorreu 25 dias após o plantio, conforme a exigência das espécies. As mudas de mil-folhas foram adquiridas de floricultura especializada em venda de mudas de plantas medicinais, na cidade de Montes Claros, Minas Gerais.

A colheita da melissa ocorreu 90 dias após o transplantio, juntamente com a colheita da mil-folhas. Logo após, realizou-se a determinação da massa fresca, em balança analítica. Os valores da matéria seca foram obtidos após secagem das plantas em estufa a $60^{\circ} \mathrm{C}$ até peso constante.

A colheita da alface ocorreu aos 45 dias após o seu transplantio. Realizou-se a pesagem das plantas para obter os valores da matéria fresca. A matéria seca teve seus valores determinados através da secagem do material vegetal em estufa a $60^{\circ} \mathrm{C}$ até peso constante. 
O óleo essencial da $\boldsymbol{M}$. officinalis L. foi extraído pelo método de hidrodestilação no aparelho Clevenger durante três horas, sendo utilizados 50 gramas da parte aérea das plantas frescas em balão volumétrico de $1000 \mathrm{~mL}$ contendo $500 \mathrm{~mL}$ de água. O conteúdo extraído foi pesado em balança de precisão. O teor de óleo (\%) foi calculado com base no valor da massa do óleo dividido pela matéria seca da amostra, sendo o resultado multiplicado por 100 . O rendimento do óleo essencial foi calculado com base nos valores do teor multiplicados pelos valores da massa seca das plantas utilizadas para a extração.

Analisou-se também o Uso Eficiente da Terra (UET) para ambos os consórcios com melissa. De acordo com FERREIRA (2000), este índice expressa a área que seria necessária para se obter com o cultivo solteiro os mesmos rendimentos totais conseguidos com o consórcio. Quando o valor do UET é maior que 1,0, significa que o consórcio é mais produtivo que o cultivo solteiro. É determinado pela seguinte expressão:

$$
\text { UET }=\frac{\begin{array}{c}
\text { Produção da cultura A } \\
\text { no consórcio }
\end{array}}{\begin{array}{c}
\text { Produção da cultura A } \\
\text { no cultivo solteiro }
\end{array}}+\frac{\begin{array}{c}
\text { Produção da cultura B } \\
\text { no consórcio }
\end{array}}{\begin{array}{c}
\text { Produção da cultura B } \\
\text { no cultivo solteiro }
\end{array}}
$$

Todos os dados referentes à matéria fresca e matéria seca das três espécies, assim como do teor e do rendimento do óleo essencial da melissa foram estatisticamente analisados por meio de contrastes ortogonais comparados pelo Teste de Scheffé a 1\% de probabilidade. Os contrastes analisados foram: Y1: melissa em cultivo solteiro vs melissa com milfolhas + melissa com alface; Y2: melissa em cultivo solteiro vs melissa em consórcio com mil-folhas; Y3: melissa em cultivo solteiro vs melissa em consórcio com alface; e Y4: melissa com alface vs melissa com mil-folhas. As médias das variáveis analisadas referentes aos tratamentos do cultivo solteiro de melissa e em consórcio com mil-folhas e alface foram comparadas por meio da Análise de Variância a 1\% de probabilidade, com o programa SAEG - Sistema para Análises Estatísticas (RIBEIRO JÚNIOR, 2001).

\section{RESULTADOS E DISCUSSÃO}

As médias das variáveis analisadas: matéria fresca (MF), matéria seca (MS), teor (TEOR) e rendimento (REND) do óleo essencial são apresentadas na tabela 1 , sendo que todos os resultados foram significativos pelo teste de Scheffé a $1 \%$, exceto para o teor do óleo essencial de melissa (TEOR). O cultivo solteiro de melissa apresentou os menores valores para as variáveis (MF: 56,355g; MS: 12,409g; TEOR: 0,0755\%; REND; 7,553g) quando comparado aos cultivos consorciados, sendo que o plantio consorciado com alface resultou nos maiores valores para as médias deste experimento (MF: 160,796g; MS: 23,508g; TEOR: 0,1903\%; REND: 19,033g), seguido pelo consórcio com milfolhas (MF: 141,248; MS: 23,258; TEOR: 0,1620\%; REND: 16,205). De acordo com Heredia Zárate (1990) apud MAIA et al. (2008), a escolha das culturas para realização do consórcio pode influenciar na produção das espécies envolvidas, haja vista que desempenham o que é denominado de cooperação mútua, utilizando todos os fatores de produção do meio, com vantagens para as espécies do consórcio. ABREU et al. (2005) relatam que o sistema de cultivo consorciado possibilita o aumento do conteúdo de matéria orgânica, a melhoria das propriedades químicas do solo, a redução da utilização de produtos químicos e a manutenção e melhoria da umidade do solo, fatores estes que podem ter contribuído para o melhor desenvolvimento dos cultivos consorciados neste trabalho. Avaliando o consórcio de melissa com alface, FONSECA (2009) encontrou os maiores valores para matéria fresca também no cultivo consorciado. ARASHIRO et al. (2011), pesquisando o consórcio entre alecrim (Rosmarinus officinalis L.) e mil-folhas, relatam, da mesma forma, um aumento no rendimento do óleo essencial do alecrim, quando em consórcio.

As estimativas dos contrastes estão apresentadas na tabela 2. Y1, Y2 e Y3 obtiveram diferenças significativas a $1 \%$ de probabilidade

Tabela 1 - Médias dos tratamentos para a matéria fresca (MF), a matéria seca (MF), o teor de óleo (TEOR) e o rendimento de óleo (REND.) da parte aérea das plantas de melissa (Melissa officinalis L.) em cultivo solteiro e consorciado.

\begin{tabular}{lllll}
\hline Tratamentos & MF (g) & MS (g) & TEOR (\%) & REND. (g) \\
\hline $\mathrm{M}+\mathrm{M}^{1}$ & 56,355 & 12,409 & $0,0755^{\mathrm{ns}}$ & 7,553 \\
$\mathrm{M}+\mathrm{Mil}^{2}$ & 141,248 & 23,258 & $0,1620^{\mathrm{ns}}$ & 16,205 \\
$\mathrm{M}+\mathrm{A}^{3}$ & 160,796 & 23,508 & $0,1903^{\mathrm{ns}}$ & 19,033 \\
$\mathrm{CV}(\%)$ & 20,2 & 13,8 & 26,5 & 27,7 \\
\hline
\end{tabular}

Melissa e melissa $\left(M+M^{1}\right)$, melissa e mil-folhas $\left(M+M i l^{2}\right)$ e melissa e alface $\left(M+A^{3}\right)$.

ns não significativo, pelo teste de Scheffé a $1 \%$. 
Tabela 2 - Estimativa dos contrastes para matéria fresca (g), matéria seca (g), teor do óleo essencial (\%) e rendimento do óleo (g), em cultivo solteiro da melissa (Y1), em cultivo consorciado com mil-folhas (Y2), em consórcio com alface (Y3) e a estimativa do contraste entre os plantios consorciados (Y4).

\begin{tabular}{|c|c|c|c|c|}
\hline \multirow{2}{*}{ Contrastes } & \multirow[b]{2}{*}{ Matéria Fresca (g) } & \multirow[b]{2}{*}{ Matéria seca (g) } & \multirow[b]{2}{*}{ Teor de óleo (\%) } & \multirow[b]{2}{*}{ Rendimento do óleo (g) } \\
\hline & & & & \\
\hline Y1 & $132,26 * *$ & $25,068 * *$ & $-0,2013^{\mathrm{ns}}$ & $17,934^{* *}$ \\
\hline Y2 & $-84,89 * *$ & $-10,85^{* *}$ & $-0,115^{\mathrm{ns}}$ & $-8,652 * *$ \\
\hline Y3 & $-104,44^{* *}$ & $-11,099 * *$ & $-0,0865^{\mathrm{ns}}$ & $-11,48 * *$ \\
\hline Y4 & $19,55^{* *}$ & $0,25^{\mathrm{ns}}$ & $-0,0283^{\mathrm{ns}}$ & $2,828^{\mathrm{ns}}$ \\
\hline
\end{tabular}

Y1 (melissa em cultivo solteiro vs melissa com mil-folhas + melissa com alface); Y2 (melissa em cultivo solteiro vs melissa com milfolhas); Y3 (melissa em cultivo solteiro vs melissa com alface); Y4 (melissa com alface vs melissa com mil-folhas).

** significativo a $1 \%$ e ns não significativo, pelo teste de Scheffé.

pelo Teste de Scheffé para matéria fresca, matéria seca e rendimento de óleo essencial. Y4 apresentou diferença significativa apenas para matéria fresca. $\mathrm{O}$ teor de óleo essencial não foi significativo em nenhum dos contrastes. De acordo com os valores obtidos em Y1, o cultivo solteiro foi significativamente menor para matéria fresca, matéria seca e rendimento do óleo, quando comparado aos cultivos consorciados. O tratamento melissa com alface foi superior ao tratamento melissa com mil-folhas apenas para matéria fresca.

A estimativa do contraste do cultivo solteiro ter sido inferior aos cultivos consorciados pode ter ocorrido devido ao fato de que muitos consórcios entre plantas diferentes reduzem o risco do surgimento de pragas e de doenças, aumentando a produção e a produtividade para as espécies vegetais compatíveis (CORRÊA JÚNIOR, 2006).

SANTOS et al. (2009), cultivando a espécie medicinal capim-limão [Cymbopogon citratus (DC.) Stapf.] em cultivo solteiro e em consórcio com milfolhas, encontraram maior rendimento do óleo de capim-limão também quando em cultivo consorciado. Segundo os autores, esse incremento pode ter sido originado devido a um provável efeito alelopático, caracterizado pela interação bioquímica entre os vegetais.

De acordo com SILVA (2004) e CORRÊA JÚNIOR et al. (1994), a influência da alelopatia de mil-folhas sobre plantas aromáticas favorece a produção do óleo essencial destas. Isto demonstra que o consórcio com mil-folhas, quando realizado com outra medicinal, pode ser vantajoso, contudo, consorciada com a melissa, de acordo com os resultados obtidos, não apresenta diferença significativa em relação ao cultivo solteiro.

Não houve diferença estatística em nenhum dos tratamentos avaliados para o teor de óleo essencial. MAIA et al. (2009), trabalhando com a Mentha $x$ villosa L. e Ocimum basilicum L., e FONSECA (2009), utilizando Ocimum basilicum L. e Melissa officinalis L. obtiveram resultados semelhantes. OLIVEIRA (2011) explica que o teor de óleo essencial está ligado a uma característica genética e, por isso, independe da quantidade de biomassa produzida pela planta. Portanto, segundo o autor, é uma variável mais difícil de ser alterada, quando comparada ao rendimento de óleo essencial.

NETTO \& RAFFAELLI (2004), aprofundando os conhecimentos sobre o cultivo de mil-folhas para a produção e extração de seu óleo essencial, obtiveram um valor médio de 83,43g planta $^{-1}$ de MF, sendo aproximadamente $46 \%$ de umidade e 54\% de MS em cada planta. VIDIGAL et al. (1995), analisando a resposta da alface ao efeito residual da adubação orgânica, obtiveram um valor de 202,287g planta $^{-1}$ de MF para as alfaces sem adição de compostos orgânicos no plantio. Isso correspondeu a 10,723g planta $^{-1}$ de MS, demonstrando que a alface possui em torno de $94 \%$ de água em sua composição. O fato de a alface possuir MF elevada, devido ao alto teor de água em sua constituição, mais de nove décimos do que a mil-folhas, pouco menos da metade de MF, pode ser o motivo para explicar a diferença aparente de MF obtido entre os consórcios deste trabalho.

MOTA et al. (2011) avaliaram o cultivo consorciado de marcela com alface. Segundo estes autores, não foram encontradas diferenças significativas para os valores da massa fresca e seca entre o cultivo solteiro e o cultivo consorciado, diferente dos resultados deste trabalho. Porém, a marcela, em cultivo solteiro, teve a tendência de apresentar maior produção. Possivelmente, a menor competição por recursos, conforme estes autores pode ter facilitado o crescimento e desenvolvimento da espécie medicinal. 
Para o Uso Eficiente da Terra (UET), os valores encontrados para o consórcio melissa com mil-folhas foi de 3,3 e, para melissa com alface, foi de 4,7, sendo ambos os valores superiores a 1,0. Isso significa que são necessários 230\% e 370\%, respectivamente, a mais de área para que as culturas no cultivo solteiro produzam o equivalente à produção obtida no cultivo consorciado. Corroborando estes resultados, CARVALHO et al. (2009), em estudos realizados com tomate consorciado com arruda, funcho, hortelã-pimenta e manjericão, descrevem que, para os valores do UET, todos os consórcios apresentaram valores maiores que 1,0 , sendo: tomate + arruda: 2,50 ; tomate + funcho: 2,29; tomate + hortelã-pimenta: 1,67 e tomate + manjericão: 1,66 . O cultivo consorciado do tomate com essas espécies medicinais foi mais vantajoso, quando comparado com o cultivo solteiro, da mesma forma que o resultado deste trabalho.

\section{CONCLUSÃO}

O sistema de cultivo consorciado com mil-folhas e com alface proporcionou um aumento no rendimento do óleo essencial e da biomassa da espécie medicinal melissa.

\section{AGRADECIMENTOS}

Os autores agradecem à Fundação de Amparo à Pesquisa do Estado de Minas Gerais (FAPEMIG), pelo apoio financeiro na realização deste experimento. Agradecem também aos Engenheiros Agrônomos: Christiano da Conceição de Matos e Jordany Aparecida de Oliveira Gomes, pela ajuda na condução experimental. À também Engenheira Agrônoma, Giovanna Alcântara Queiroz, pela ajuda na elaboração do Abstract. Agradecem ainda à Professora Lourdes Silva de Figueiredo e aos Professores Luiz Arnaldo Fernandes e Cândido Alves da Costa, do Instituto de Ciências Agrárias da Universidade Federal de Minas Gerais, pelo valioso auxílio na correção do texto.

\section{REFERÊNCIAS}

ABREU, G.T. et al. Produção de biomassa em consórcio de aveia branca (Avena sativa L.) leguminosas forrageiras. Revista Brasileira de Agrociência, v.11, n.1, p.19-24, 2005. Disponível em: <http://www.ufpel.tche.br/faem/agrociencia/v11n1/artigo03. pdf $>$. Acesso em: 25 nov. 2012.

ARASHIRO, M.P. et al. Cultivo consorciado entre Achillea millefolium L. e Rosmarinus officinalis L. e seu efeito no rendimento do óleo essencial, biomassa e atividade antimicrobiana. Revista Saúde e Pesquisa, v.4, n.3, p.373-380, 2011. Disponível em: <http://www.alice.cnptia.embrapa.br/handle/doc/919238>. Acesso em: 30 abr. 2011.

CARVALHO, L.M. et al. Produtividade do tomateiro em cultivo solteiro e consorciado com espécies aromáticas e medicinais. Horticultura Brasileira, v.27, n.4,p.458-464, 2009. Disponível em: <http://www.scielo.
br/scielo.php?script=sci_arttext\&pid=S0102-05362009000400010 $>$. Acesso em: 26 abr. 2011. doi: 10.1590/S0102-05362009000400010.

CARVALHO FILHO, J.L.S. et al. Tolerância ao florescimento precoce e características comerciais de progênies F4 de alface do cruzamento Regina 71 x Salinas 88. Acta Scientiarum Agronomy, v.31, n.1, p.37-42, 2009. Disponível em: <http://periodicos.uem. br/ojs/index.php/ActaSciAgron/article/view/6607/6607>. Acesso em: 13 abr. 2011. doi: 10.4025/actasciagron.v31i1.6607.

CERNY, A.; SCHMID, K. Tolerability and efficacy or valerian/ lemon balm in healthy volunteers (a double-blind, placebocontrolled, multicentre study). Fitoterapia, v.70, n.3, p.221-228, 1999. Disponível em: <http://www.sciencedirect.com/science/ article/pii/S0367326X99000180>. Acesso em: 23 jun. 2011. doi: 10.1016/S0367-326X(99)00018-0.

CORRÊA JÚNIOR, C. et al. Cultivo de plantas medicinais condimentares e aromáticas. Curitiba: EMATER- Paraná, 1994. 151 p.

CORRÊA JÚNIOR, C. et al. Cultivo agroecológico de plantas medicinais, aromáticas e condimentares. Brasília: Ministério do Desenvolvimento Agrário, 2006. 76 p.

FERREIRA, P.V. Estatística aplicada à agronomia. Maceió: EDUFAL, 2000. 419 p.

FILGUEIRA, F.A.R. Novo manual de olericultura: agrotecnologia moderna na produção e comercialização de hortaliças. Viçosa: UFV, 2007. 421 p.

FONSECA, J.R.O. Cultivos consorciados entre alface, cenoura, manjericão e melissa. 2009. 151f. Dissertação (Mestrado em Ciências Agrárias) - Pós-graduação em Ciências Agrárias, Universidade Federal de Minas Gerais, MG.

LORENZI, H.; MATOS, F. de A. Plantas medicinais no Brasil: nativas e exóticas cultivadas. São Paulo: Instituto Plantarum, 2008. 188 p.

MAIA, J.T.L.S. et al. Produção de alface e cenoura em cultivo solteiro e consorciado com manjericão e hortelã. Revista Brasileira de Agroecologia, v.3, n.1, p.58-64, 2008. Disponível em: <http:// www.agroecologia.pro.br/arquivos/agroecologia/artigos/producao_ de_alface_e_cenoura_em_cultivo_consorciado.pdf $>$. Acesso em: 9 ago. 2013.

MAIA, J.T.L.S. et al. Influência do cultivo em consórcio na produção de fitomassa e óleo essencial de manjericão (Ocimum basilicum L.) e hortelã (Mentha $x$ villosa L.). Revista Brasileira de Plantas Medicinais, v.11, n.2, p.137-140, 2009.

MARTINS, E.R. et al. Plantas medicinais. Viçosa: UFV, 2000. 220 p.

MARTINS, M.B.G.; PASTORI, A.P. Anatomia foliar com ênfase nos tricomas secretores e análise cromatográfica do óleo essencial de Melissa officinalis L. (Lamiaceae). Revista Brasileira de Plantas Medicinais, v.6, n.2, p.77-82, 2004.

MOTA, J.H. et al. Crescimento e produção de alface e marcela em cultivo solteiro e consorciado. Acta Scientiarum Agronomy, v.33, n.2, p.269-273, 2011. Disponível em: <http://periodicos. uem.br/ojs/index.php/ActaSciAgron/article/view/4426/4426>. Acesso em: 15 abr. 2011. doi: 10.4025/actasciagron.v33i2.4426. 
NETTO, S.P.; RAFFAELLI, G. Produção experimental de milfolhas (Achillea millefolium L.), visando à extração de óleo essencial. Revista Acadêmica: ciências agrárias e ambientais, v.2, n.3, p.27-31, 2004. Disponível em: <http://www2.pucpr.br/ reol/index.php/ACADEMICA?dd1=929\&dd99=view $>$. Acesso em: 30 nov. 2012.

OLIVEIRA, A.R.M.F.de. Produção de óleo essencial de Mentha x piperita var. citrata sob diferentes condições de manejo. 2011. 83f. Dissertação (Mestrado em Produção Vegetal) - Universidade Estadual de Santa Cruz.

RIBEIRO, P.G.F.; DINIZ, R.C. Plantas aromáticas e Medicinais: cultivo e utilização. Londrina: IAPAR, 2008. 218 p.

RIBEIRO JÚNIOR, J.I. Análises estatísticas no SAEG. Viçosa: UFV, 2001. 301 p.

ROVERATTI, D.S. Plantas medicinais. São Paulo: Unimarco, 1999. $128 \mathrm{p}$.

SADRAEI, H. et al. Relaxant effect of essencial oil of Melissa officinalis (L.) and citral on rat ileum contractions. Fitoterapia, v.74, n.5, p.445-452, 2003. Disponível em: <http://www. sciencedirect.com/science/article/pii/S0367326X03001096>. Acesso em: 10 jul. 2011. doi: 10.1016/S0376-326X(03)00109-6.

SANTOS, A. et al. Determinação do rendimento e atividade antimicrobiana do óleo essencial de Cymbopogon citratus (DC.) Stapf em função de sazonalidade e consorciamento. Revista
Brasileira de Farmacognosia, v.19, n.2a, p.436-441, 2009. Disponível em: <http://www.scielo.br/scielo.php?script=sci_artte xt\&pid=S0102695X2009000300017> . Acesso em: 25 abr. 2011. doi: 10.1590/S0102-695X2009000300017.

SARTÓRIO, M.L. Cultivo orgânico de plantas medicinais. Viçosa: Aprenda Fácil, 2000. 224 p.

SILVA, F. et al. Qualidade pós-colheita de mil-folhas (Achillea millefolium L.) em cultivo associado à salsa (Petroselinum crispum (Miller) A. W. Hill). Revista Brasileira de Plantas Medicinais, v.2, n.1, p.33-36, 1999.

SILVA, F.M. Extração aquosa de aleloquímicos e bioensaios laboratoriais de alelopatia. 2004. 87f. Dissertação (Mestrado em Botânica)-UniversidadeFederaldoRioGrandedoSul, RS. Disponívelem: <http://www.lume.ufrgs.br/bitstream/handle/10183/4729/000414428. pdf?sequence=1>. Acesso em: 6 jun. 2011.

TEKEL, J. et al. Determination of uracil herbicide residues and components of essential oil in Melissa officinalis L. in its main development phases. Journal of Essencial Oil Research, v.9, n.1, p.63-66, 1997. Disponível em: <http://www.tandfonline.com/doi/ab s/10.1080/10412905.1997.9700716?journalCode=tjeo20\#preview $>$. Acesso em: 25 abr. 2011. doi:10.1080/10412905.1997.9700716.

VIDIGAL, S.M. et al. Resposta da alface (Lactuca sativa L.) ao efeito residual da adubação orgância: I Ensaio de campo. Revista Ceres, v.42, n.239, p.80-88, 1995. Disponível em: <http://www.ceres.ufv.br/ceres/ visao/site/onlineArtigo.php?revistaCod=60>. Acesso em: 13 jun. 2011. 